\title{
Lycopene recovery from tomato peel under mild conditions assisted by enzymatic pre-treatment and non-ionic surfactants*
}

\author{
Emmanouil H. Papaioannou ${ }^{\bowtie}$ and Anastasios J. Karabelas \\ Laboratory of Natural Resources and Renewable Energies, Chemical Process Engineering Research Institute (CPERI), Centre for Research and \\ Technology-Hellas (CERTH), Thessaloniki, Greece
}

\begin{abstract}
The tomato processing industry generates large quantities of tomato peel residues, usually creating environmental problems. These residues are a significant source of lycopene, thus providing an attractive alternative for profitable handling of these otherwise problematic byproducts. The enzymatic pretreatment of these residues for lycopene recovery has already been employed, although the use of surfactants for enhancing the recovery has not been examined so far. The enzymatic pretreatment of tomato peels, using two commercially available pectinolytic enzyme preparations, was evaluated suggesting that there is an optimum pretreatment time of about $1 \mathrm{~h}$, enzyme amount 250 Units $/ \mathrm{mL}$ and no significant pH influence. Lycopene surfactant - assisted extraction was further investigated, showing that, among eight surfactants used, the most suitable was "Span 20", with an optimum ratio of 6-7 surfactant molecules per lycopene molecule. Sequential enzymatic pretreatment and surfactant-assisted extraction (30 min for each step) was evaluated leading to an improved lycopene extraction yield, with a somewhat smaller surfactant molar ratio (i.e. 4-5). In the latter case, the yield of lycopene recovery was almost four times greater compared to just 1 hr enzymatic pretreatment, and was approximately ten times greater compared to the recovery from untreated peels. Furthermore, such lipophilic compound recovery, avoiding the use of organic solvents, is environmentally attractive and ensures direct lycopene use in the food and cosmetics industries.
\end{abstract}

Key words: tomato peel lycopene recovery, enzymatic pre-treatment, non-ionic surfactant, carotenoids recovery, agro-food wastes

Received: 14 October, 2011; accepted: 01 March, 2012;

available on-line: 17 March, 2012

\section{INTRODUCTION}

Million tons of tomatoes are processed yearly to produce juice, sauces, purees, pastes, and canned tomatoes, resulting in large amounts of tomato peel, pulp, and seed as industrial waste (called in general tomato pomace). Tomato pomace is currently disposed of or used as animal feed, but the abundance of lycopene in the peel suggests the possibility of utilizing it as a cheap source of lycopene, providing also revenues that could partially off-set the cost for further effective management of the remaining wastes. However, despite such high lycopene content, the extraction technologies used at present do not seem to allow its efficient recovery.

Lycopene $(\psi, \psi$-carotene $)$ is an acyclic tetraterpenic hydrocarbon with 13 carbon-carbon double bonds, 11 of which are linearly conjugated, and is responsible for the deep red color of ripe tomatoes. Lycopene has attracted in recent years considerable attention for its possible role in disease prevention (Omoni \& Aluko, 2005). The high degree of double bond conjugation confers strong antioxidant properties to the molecule, making lycopene one of the most potent antioxidants (Di Mascio et al., 1989).

Commercial lycopene is available as standardized tomato extract or from chemical synthesis. Market trends indicate a growing demand for the former product, because of its natural origin and the presence of other phytochemicals, such as $\beta$-carotene, phytoene and phytofluene, which are believed to act synergistically with lycopene (Shixian et al., 2005). Lycopene is in high demand by the pharmaceuticals industry as well as by the food, and cosmetics industries (Borguini \& Torres, 2009). Natural lycopene is produced today mainly by extraction and concentration from whole tomato fruits, that are grown specifically for this purpose. The commercially available product, however, is very expensive and current production from whole tomato fruits is small compared to projections of future demand. This has prompted the search for alternative sources of lycopene and appropriate technologies for its recovery. Lycopene is found predominantly in the chromoplast of plant tissues. In tomatoes, lycopene biosynthesis increases sharply during the ripening process, as the chloroplast undergoes transformation to chromoplast.

The peel fraction of tomato waste contains lycopene up to five times more than the pulp (on wet basis), but its high moisture levels and susceptibility to microbial spoilage make the storage and processing of this material quite problematic. Lycopene extractability by conventional food-grade organic solvents, such as hexane, ethanol and ethyl acetate, is extremely low, at least under the conditions that normally preserve the activity of the carotenoid in vivo. Lycopene recovery is achieved by pigment extraction from the natural product matrix by organic solvents and quantification by using the spectrophotometeric or HPLC methods (Olives Barba et al., 2006; Kaur et al., 2008; Zuorro \& Lavecchia, 2010). Low extraction efficiencies can be attributed to the difficulty of solvent molecules to penetrate the compact tomato peel tissue and solubilize the pigment, which is deeply embedded within the chromoplast membrane structures (Harris \& Spurr, 1969). Tomato peel is a highly struc-

e-mail: empapaio@cperi.certh.gr

* Presented at the 16th International Symposium on Carotenoids, 17-22 July, 2011, Kraków, Poland

Abbreviations: CPE, cloud point extraction; HLB, hydrophilic lipophilic balance. 
tured plant material containing many different polysaccharide components, such as cellulose, hemicelluloses and pectins (Gross, 1984). In theory, the extraction efficiency could be improved by using more severe extraction conditions, but the risk for lycopene to undergo oxidative degradation would proportionally increase (Xianquan et al., 2005). The optimum extraction conditions depend on the processing technique used to obtain the food product. For example, longer extraction times and more extraction cycles are required to efficiently extract lycopene from raw tomato and tomato skin (Kaur et al., 2008), compared to the tomato paste (Sadler et al., 1990). In the unprocessed tomato, the lycopene is bound within the cellular structures, while the cells in the tomato paste have been weakened by processing, resulting in the higher extraction efficiency of lycopene from the tomato paste.

The enzymatic pretreatment of agro-wastes is an already established approach, with many applications for recovering compounds of biological significance and other high added value products from their compact highly structured plant tissue. Since the plant cell wall is comprised of cellulose and pectins, cellulases and pectinases have been used for this purpose. Cell-wall degrading enzymes have been successfully used to enhance the release of a variety of components, including phenolic compounds (Landbo \& Meyer, 2001), non-volatile grape aroma precursors (Bautista-Ortín et al., 2005) and carotenoids (Barzana et al., 2002; Zuorro \& Lavecchia, 2010), from a variety of plant materials. In light of the above considerations, we have explored the possibility of using cell-wall degrading enzymes, i.e., enzymes that are capable of hydrolyzing the pectins of the plant structures where the pigment accumulates, as a mild and efficient means to facilitate recovery of lycopene. In this paper, with a view to industrial applications, attention is focused on a method utilizing readily available enzyme preparations and organic solvent, approved for food applications, such as ethyl acetate.

Surfactants have been successfully used for Cloud Point Extraction (CPE) of numerous analytes of biological interest, such as proteins, enzymes, phenols from aqueous solutions (Materna \& Szymanowski, 2002), polyphenols from wine sludge (Chatzilazarou et al., 2010), both hydrophobic and hydrophilic ginsenosides (Fang et al., 2000). However, the use of surfactants to facilitate the recovery of such lipophilic compounds as carotenoids from their natural matrices is another alternative, never examined before in tomato peel residue and especially in combination with enzymatic pre-treatment.

\section{MATERIALS AND METHODS}

Materials. The following enzyme preparations, all from fungal sources and in liquid form, were used: Citrozym $^{\circledR}$ CEO 9500 PGU/mL and Citrozym ${ }^{\circledR}$ Ultra L 4500 PECTU/mL, from Novozymes (Denmark). The surfactants: Span20 (Hydrophilic Lipophilic Balance, HLB: 4.3), Span40 (HLB: 6.7), Span60 (HLB: 5), Span85 (HLB: 1.8), Tween20 (HLB: 16.7), Tween80 (HLB: 15), Tween85 (HLB: 11) and Triton X-100 (HLB: 13.5) were all from Sigma-Aldrich Inc. Chemicals Co (Germany). In all experiments an amount of $0.22 \mathrm{~g}$ tomato peel from the local market was used, treated in a house blender and partially dehydrated.

Enzymatic pretreatment. The tomato peels were contacted with pectinolytic enzyme preparations, diluted to a final volume of $3.5 \mathrm{~mL}$. The reaction mixture was prepared by dissolving the appropriate amount of concentrated liquid enzyme preparation in distilled water or in buffer solution of $\mathrm{pH} 5$ in order to achieve the desirable final enzyme activity. The enzymes were examined for the pretreatment of tomato peels, under the same dilution of 250 enzyme Units/mL for various pretreatment times $(15,30,60,120$ and $180 \mathrm{~min})$, and $\mathrm{pH} 5.5$ and 5 (125 and 750 enzyme Units $/ \mathrm{mL}$ ). The $\mathrm{pH}$ of the diluted enzyme solution without adjustment was 5.5. The influence of different enzyme amount was examined using different enzyme dilutions for $1 \mathrm{~h}$ pretreatment (i.e. 125, 250, 500, 750, 1000, 1500 and 2000 enzyme Units/mL).

Surfactant assisted extraction. Tomato peels were placed in vials with different surfactants in distilled water, with final solution volume $5 \mathrm{~mL}$ and a molar ratio 10 surfactant molecule per molecule of total calculated lycopene. In addition, the influence of different surfactant concentrations was examined with the best surfactant, i.e. Span 20. In all cases the surfactant was initially added to water and subjected to intense stirring at $500 \mathrm{rpm}$ until a stable emulsion was obtained.

Enzymatic pretreatment and surfactant assisted extraction. A combination of enzymatic pretreatment for $30 \mathrm{~min}$ (with an enzyme solution with activity 250 enzyme Units $/ \mathrm{mL}$ ) and subsequently $30 \mathrm{~min}$ surfactant assisted extraction with Span 20 was used using different molar ratios (1-11) in respect of total calculated lycopene content, in a final solution volume of $5 \mathrm{~mL}$. All experiments were carried out at room temperature under stirring $(250 \mathrm{rpm})$ in triplicate and the average is reported here $(\mathrm{SD} \leq 5 \%)$. At the end of all examined cases of pretreatment, $5 \mathrm{~mL}$ of ethyl acetate was poured into the flasks and the system was kept under stirring for further $10 \mathrm{~min}$. Subsequently, a sample of the solvent was withdrawn, filtered and analyzed spectrophotometrically for lycopene content at $470 \mathrm{~nm}$ using a Shimanzu U-1700 spectrometer.

\section{RESULTS AND DISCUSSION}

\section{Enzymatically assisted lycopene extraction}

Characterization of lycopene fraction in peel (with a moisture content of $77.0 \pm 1.4 \mathrm{wt}^{\mathrm{O}} \%$ ) provided an average content of $643 \pm 17 \mu \mathrm{g} / \mathrm{g}$, after three extraction cycles ( $2 \mathrm{~h}$ each) with ethyl acetate, leaving after the extraction a colorless white peel tissue. The reported lycopene recovery yields are expressed as the percentage of the lycopene amount extracted in a single extraction step over the total amount of lycopene in the peels that could be extracted after three repeated extraction cycles $(2 \mathrm{~h}$ each). The yield of lycopene extraction from untreated tomato peels after just $1 \mathrm{~h}$ stirring in distilled water was $6.08 \pm 0.3 \%$ (Fig. $1 \mathrm{~b}$ and c). In general, the use of commercial pectinolytic enzyme preparations and the subsequent extraction with ethyl acetate under the specific experimental conditions, lead to an increase in lycopene recovery of about $9.5-11 \%$, compared to the total recovered amount. An incubation time of $1 \mathrm{~h}$ was found to be optimum for the enzymatic pre-treatment of peels (Fig. 1a), for both enzyme preparations, under the same enzymatic activity of 250 Units $/ \mathrm{mL}$. Afterwards, the influence of the solution with different enzyme activity in the pre-treatment of peels has been investigated, which shows that a solution with enzyme activity 250 Units/ $\mathrm{mL}$ and $1 \mathrm{~h}$ was effective in extracting the lycopene from the peels (Fig. 1b). The decrease observed in the lycopene content with increasing solution enzyme activ- 

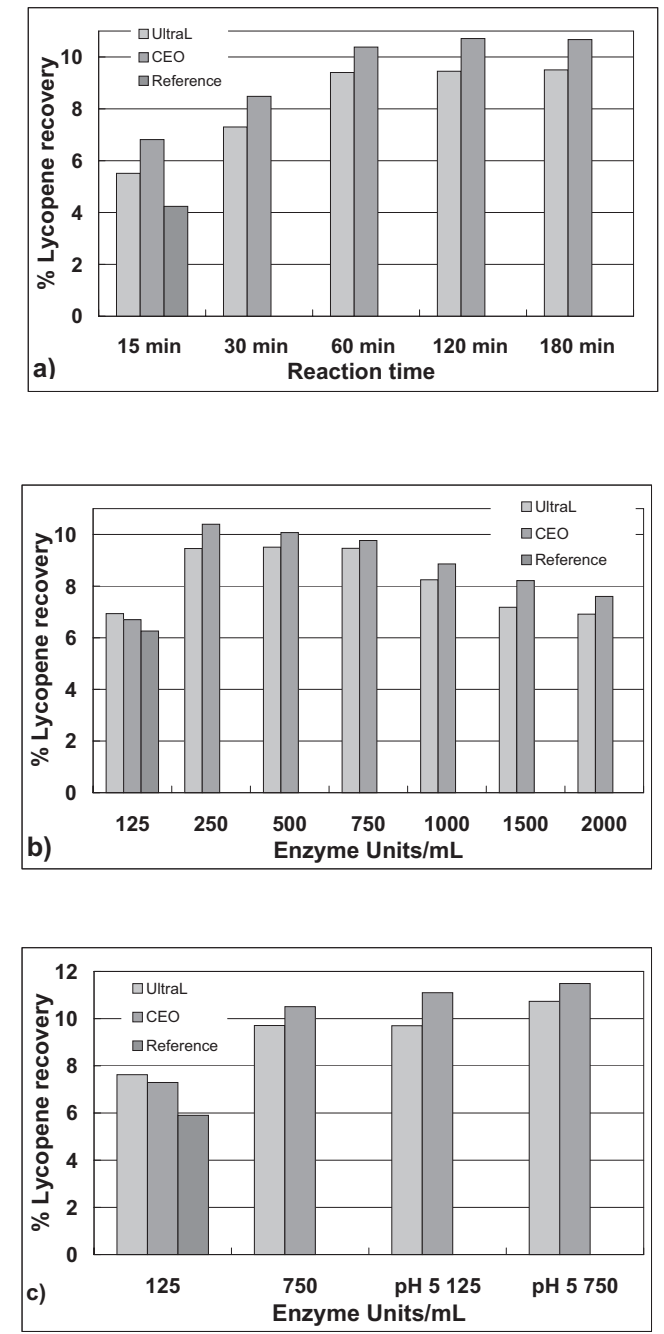

Figure 1. Factors influencing the enzymatic pre-treatment of tomato peels:

(a) time, (b) enzyme amount, and (c) pH.

ity (Fig. 1b) may be due to its ease of extraction from the peel mass and therefore to its prompt oxidation under the examined conditions. The effect of $\mathrm{pH}$ on the peels enzymatic pre-treatment did not exhibit any significant alteration regarding the examined enzymes and concentrations (Fig. 1c). The optimum $\mathrm{pH}$ range is 5.5 and 4.5 for Citrozym $^{\circledR}$ CEO and Citrozym ${ }^{\circledR}$ Ultra L respectively, according to Zuorro \& Lavecchia (2010). In conclusion, the Citrozym ${ }^{\circledR} \mathrm{CEO}$ appears to perform better (Fig. 1a-c) with an optimum concentration $250 \mathrm{U} /$ $\mathrm{mL}$ for $1 \mathrm{~h}$, while the $\mathrm{pH}$ does not significantly affect the pre-treatment.

\section{Surfactant assisted lycopene extraction}

Eight commonly used surfactants with quite broad range of Hydrophilic Lipophilic Balance (HLB) were examined. It was found that surfactants with a HLB value in the range 4 to 7 (i.e. Span 20, Span 40 and Span 60) exhibited the best performance (Fig. 2a); Span 20 was the most effective, resulting in lycopene recovery about 23-25\%. Furthermore, the influence of Span 20 over lycopene molar ratio on extraction was investigated (Fig. 2b). It was found that lycopene recovery was strongly dependent on Span 20 concentration; i.e. the recovery increased with Span 20 concentration, up to
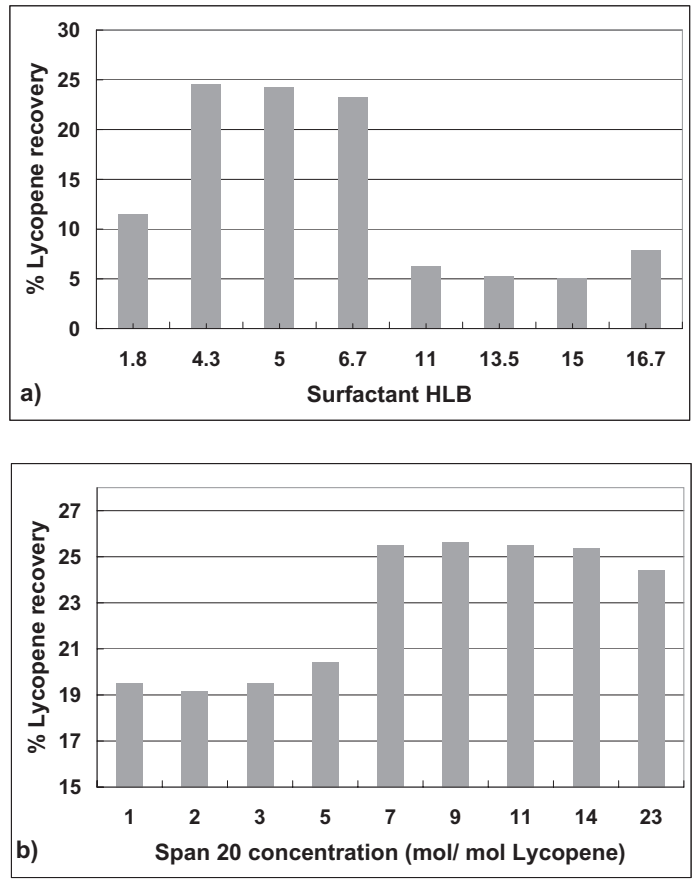

Figure 2. Surfactant assisted lycopene recovery from tomato peels for:

(a) various surfactants at the same concentration, and (b) various Span 20 concentrations.

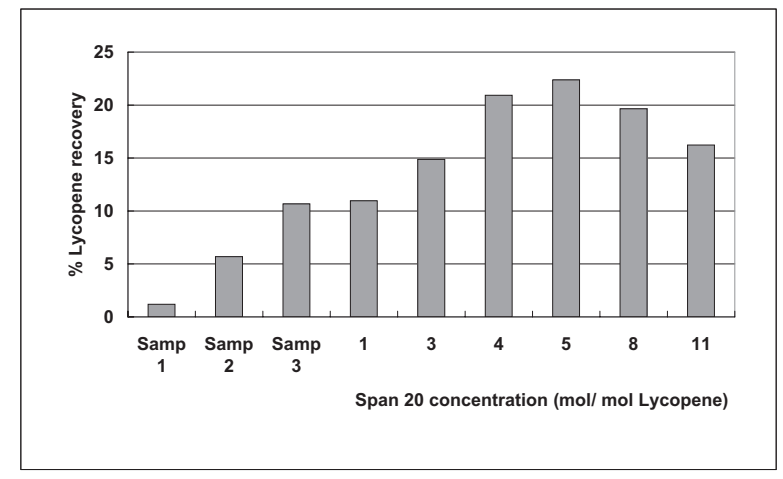

Figure 3. Results of combined enzyme pre-treatment and surfactant assisted extraction; data for six different molar ratios of Span 20 over lycopene.

Additional data: Samp 1, untreated peels; Samp 2, enzyme treated peels ( 250 enzyme Units $/ \mathrm{mL}$ ) without surfactant; Samp 3, surfactant assisted extraction without enzymatic pre-treatment (molar ratio of Span 20 over lycopene equal to six).

a specific ratio, exhibiting an optimum range of 5 to 7 (Fig. 2b) and lycopene recovery about $20-25 \%$. It should be mentioned here in respect of an industrial application that a low ratio indicates an economically more effective process (less surfactant used) and an easier separation of the entrapped (into the emulsion) lycopene from the surfactant, if it is necessary.

\section{Combined enzymatic pretreatment and surfactant assisted extraction}

The results of this sequential treatment are shown in Fig. 3, for six surfactant (Span 20) over lycopene molar ratios (i.e. $1,3,4,5,8,11$ ); an improvement is obtained in lycopene recovery, with a somewhat lower molar ratio of surfactant over lycopene molecule, i.e. 4 to 5. Fig. 3 also shows the lycopene recovery from totally untreated 
peels (Samp1), from enzyme treated peels (Samp 2) and from peels treated $1 \mathrm{~h}$ only with Span 20 and molar ratio of surfactant to lycopene equal to six (Samp 3). Combined treatment leads to lycopene recovery almost four times greater, compared to simple $1 \mathrm{hr}$ enzymatic pretreatment (Samp 2), and approx. ten times greater compared to recovery from untreated peels (Samp1).

\section{CONCLUSIONS}

The results of this study show that the recovery of lycopene from the peel fraction of tomato processing waste can be greatly enhanced by the combined use of commercial enzyme preparation and surfactant assisted extraction. In particular, initial pretreatment of tomato peels with Citrozym ${ }^{\circledR}$ CEO followed by surfactant assisted extraction, for $30 \mathrm{~min}$ in each step, resulted in extraction yields four and ten times greater compared to enzymatically pretreated and untreated peels, respectively. This fact, together with the comparatively low cost of commercial food-grade enzyme preparations and surfactants used, lend strong support to the possible implementation of the process at industrial scale. Furthermore, the recovered lycopene is in the form of an aqueous emulsion, readily usable for applications in the food and cosmetics industries; this is of paramount importance for such a lipophilic compound recovery, avoiding the use of organic solvents and thus being more environmentally friendly.

\section{Acknowledgments}

The authors wish to thank Novozymes (Dr Höhn Albrecht) and Alinda S.A. Greece (Mrs Gisli Alexandra) for donating the enzyme preparations.

\section{REFERENCES}

Barzana E, Rubio D, Santamaria RI, Garcia-Correa O, Garcia F, Ridaura Sanz VE, López-Munguía A (2002) Enzyme-mediated solvent extraction of carotenoids from Marigold flower (Tagetes erecta). J Agric Food Chem 50: 4491-4496.

Bautista-Ortín AB, Martínez-Cutillas A, Ros-Garcia JM, López-Roca JM, Gómez-Plaza E (2005) Improving colour extraction and stability in red wines: the use of maceration enzymes and enological tannins. Int J Food Sci Technol 40: 867-878.

Borguini RG, Torres EAFD (2009) Tomatoes and tomato products as dietary sources of antioxidants. Food Rev Int 25: 313-325.

Chatzilazarou A, Katsoyannos E, Gortzi O, Lalas S, Paraskevopoulos Y, Dourtoglou E, Tsaknis J (2010) Removal of polyphenols from wine sludge using cloud point extraction. $J$ Air \& W Waste Manage Assoc 60: $454-459$.

Di Mascio P, Kaiser S, Sies H (1989) Lycopene as the most efficient biological carotenoid singlet oxygen quencher. Arch Biochem Biophys 274: 532-538.

Fang Q, Yeung HW, Leung HW, Huie CW (2000) Micelle-mediated extraction and preconcentration of ginsenosides from Chinese herbal medicine. I Chromatogr A 904: 47-55.

Gross KC (1984) Fractionation and partial characterization of cell walls from normal and non-ripening mutant tomato fruit. Physiol Plant 62: 25-32.

Harris WM, Spurr AR (1969) Chromoplasts of tomato fruits. II. The red tomato. Am J Bot 56: 380-389.

Kaur D, Wani AA, Oberoi DPS, Sogi DS (2008) Effect of extraction conditions on lycopene extractions from tomato processing waste skin using response surface methodology. Food Chem 108: 711-718.

Landbo AK, Meyer AS (2001) Enzyme-assisted extraction of antioxidative phenols from black currant juice press residues (Ribes nigrum). $J$ Agric Food Chem 49: 3169-3177.

Materna K, Szymanowski J (2002) Separation of phenols from aqueous micellar solutions by cloud point extraction. J Colloid Interface Sci 255: 195-201.

Olives Barba AI, Hurtado MC, Mata MCS, Ruiz VF, Tejada MLSd (2006) Application of a UV-vis detection-HPLC method for a rapid determination of lycopene and $\beta$-carotene in vegetables. Food Chem 95: 328-336.

Omoni AO, Aluko RE (2005) The anti-carcinogenic and anti-atherogenic effects of lycopene: a review. Trends Food Sci Technol 16: $344-350$.

Shixian Q, Dai Y, Kakuda Y, Shi J, Mittal G, Yeung D, Jiang Y (2005) Synergistic anti-oxidative effects of lycopene with other bioactive compounds. Food Rev Inter 21: 295-311.

Xianquan S, Shi J, Kakuda Y, Yueming J (2005) Stability of lycopene during food processing and storage. J Med Food 8: 413-422.

Zuorro A, Lavecchia R (2010) Mild enzymatic method for the extraction of lycopene from tomato paste. Biotechnol Biotechnolog Equipment 24: $1854-1857$. 